\title{
Towards Bioactive Containing Restorative Materials: From Design to Testing In vitro Approach
}

\author{
V. Tamara Perchyonok ${ }^{1 *}$, Riaan Mulder ${ }^{2}$, Shengmiao Zhang ${ }^{3}$ and Sias R Grobler ${ }^{2}$ \\ ${ }^{1}$ VTPCHEM PTY LTD, Glenhuntly, Melbourne, 3163, Australia \\ ${ }^{2}$ Oral and Dental Research Institute, Faculty of Dentistry, University of the Western Cape, Private Bag X1, Tygerberg \\ 7505, Cape Town, South Africa \\ ${ }^{3}$ School of Material Science and Engineering, East China University of Science and Technology, 130 Meilong Road,
}

Shanghai, 200237, China

Received: June 04, 2015; Accepted: July 15, 2015; Published: August 04, 2015

*Corresponding author: V. Tamara Perchyonok,VTPCHEM PTY LTD, Glenhuntly, Melbourne, 3163, Australia, E-Mail:tamaraperchyonok@gmail.com

\begin{abstract}
In any repair of a tooth with permanent restorative materials, the interface is always a sensitive region. The appearance of adhesive materials was a great step forward in dealing with the problems of this region and improving the overall performance of the restorations. However, contemporary adhesive materials do have a major disadvantage, namely that their durability is limited, a limitation which often arises due to their inadequate marginal adaptation. Restorative materials in the new era aim to be "bio-active" and longlasting.
\end{abstract}

As part of our continuous interest in developing the novel bioactive containing restorative materials, we evaluated the effect of the additional bio-actives (such as chitosan, $\beta$-carotene, guar gum resin and the combination of the materials) to the commercially available flowable restorative materials such as Premise on the volumetric shrinkage, flexural strength, compressive strength, the surface hardness of the "bio-active" containing composite.

Materials and Methods: The bioactive modified restorative materials were prepared by dispersion of the corresponding component with the addition of commercially available flowable restorative material. The surface morphology (SEM) of the freshly prepared restorative materials as well as reactive surface of the material after 24 hours and 3 months storage in artificial saliva has been performed. The physicochemical properties such volumetric shrinkage, Vickers Hardness and flexural strength of the bio-active restorative materials have been measured and are reported. The effect of the bioactive additionto the commercially available flowable restorative materials such as Premise on the shear bond strength of dentin has been evaluated.

Results: The SEM images were obtained to characterize the microstructure of the freeze-dried modified restorative material as well as evaluated the durability of the bioactive restorative materials after 24 hours and 3 month exposure to artificial saliva.All bioactive containing flowable restorative materials gave significantly $(P<0.05$; non-parametric ANOVA test) higher shear bond values $(P<0.05)$ than dentin treated or not treated with phosphoric acid.Volumetric changesdue to polymerization in modified composites have been explored using an electronic mercury dilatometer. The average volumetric change reached a plato at about 20 seconds for the samples tested and the total volumetric changes were reached at 25 seconds. The average for the control Premise samples had a total volumetric change of $2.74 \%$. Guar/Premise had the largest volumetric change from all the modified Premise samples (2.41\%). The Chitosan/Premise $(1.07 \%)$ had the least volumetric change, followed by $\beta$-Carotene/ Chitosan/Premise (1.63\%) and $\beta$ Carotene/Premise (1.75\%). The volumetric change starts at different time intervals for all the materials. The Turkey-Kramer multiple comparison test on the rate of shrinkage slopes has confirmed the statements $(\mathrm{p}<0.05)$.TheVickers Hardnessof the bio-active composites such as $\beta$-carotene/chitosan/ Premise (37.4VH), Guar Gum/Premise (36.2VH), $\beta$-carotene/ Premise (36VH), Chitosan/Premise (5.2 VH) versus Premise control $(37.6 \mathrm{VH})$ were measured and relevant clinical applications have been elaborated.

All modified bio-active flowable composites, which an exception of chitosan and $\beta$-carotene containing materials have shown comparable compressive and flexural strength to the commercially available Premise material which makes the newly modified bioactive composites ideal candidates for further evaluation and development is bio-functional restorative materials.

Conclusion: The materials were tested using effective in-vitro development of "dual function restorative materials". We quantified the effects of functional designer biomaterials on the dentin bond strength of composite, measure volumetric changes due to polymerization in dental resins as well as Vickers hardness and \% of water uptake by the modified composites. Within the limitations of the study design chitosan based hydrogels are suitable materials for functional restorative applications in vitro. Cytotoxicity data is currently being evaluated in our laboratory.The clinical significance is that the decrease in volumetric change will have a positive effect on the stress formation on the tooth/adhesive/restoration interface.The additional therapeutic benefits of addition of the bioactive materials such as chitosan, beta-carotene, guar gum resin as well as combination are described.

Keywords: antioxidants; functional biomaterials; dentin bonding; volumetric changes; dialometer 


\section{Introduction}

In any repair of a tooth with permanent restorative materials, the interface is always a sensitive region. The appearance of adhesive materials was a great step forward in dealing with the problems of this region and improving the overall performance of the restorations [1]. However, contemporary adhesive materials do have a major disadvantage, namely that their durability is limited, a limitation which often arises due to their inadequate marginal adaptation. The factors that are most commonly attributed to failure are the harsh conditions of the oral environment, such as temperature change, the fatigue of the bond owing to tooth flexure, the presence of bacterial enzymes, and the aqueous environment [2]. Good marginal adaptation decreases microleakage considerably and also reduces the postoperative sensitivity and the occurrence of secondary caries [3]. It thus improves the longevity of the fillings. Restorative materials in the new era aim to be "bio-active", bio-functional and longlasting by maintaining appropriate mechanical, physical, and adhesive properties. The current trend in restorative dentistry has been greatly influenced by better understanding of the caries process, advances in the dental materials science and increased demand for bioactive restorations, which prevent the recurrence of carious lesions. Recurrent dental caries has been associated with deteriorating restorative materials, providing a potential pathway to the cariogenic microbes.

For last 20 years, the development of resin based dental material has been more focused to get minimum polymerization shrinkage with maximum degree of conversion along with better mechanical, thermal, optical properties by the advancement in filler technology [4]. The properties of dental composites are highly dependent on the characteristics of the fillers like the shape, size, surface area and porosity. Volumetric change of dental resins has been extensively researched in the literature[1-3]. The $2 \mathrm{~mm}$ layering technique has been the increment thickness of choice in order to overcome the negative effects of volumetric change and the resultant stresses that develop in the bonded surfaces of the tooth structure[4-7].

The increase of the molecular weight of the organic component of a dental resin has been shown as a method of decreasing the volumetric change and improving some physical properties $[8,9]$.

To pursue our continuous interest in developing and functionalizing dual function restorative materials we decided to investigate the effects of the addition of chitosan, $\beta$-carotene, guar gum resin and the combination of the chitosan/ $\beta$-carotene as functional additives to commercially available flowable restorative materials in order to evaluate its effects on the performance.

\section{Materials}

Chitosan (Aldrich, Australia), glycerol (Sigma, USA), glacial acetic acid (E. Merck, Germany) were used as received. The degree of de-acetylation of typical commercial chitosan used in this study is $87 \%$. Chitosan with molecular weight $2.5 \times 10^{3} \mathrm{KD}$ was used in the study. The isoelectric point is 4.0-5.0. $\beta$-carotene
(Biovea, Australia) and Guar Gum ( Guar Gum Australia) were used as received.

The flowable composite Premise by Kerr (California, USA) Lot: 4485575 exp 2014-02 shade A3 was used as the standard control material. Experiments were repeated 5 timesfor each group, including control samples. Furthermore, the volumetric change of the Premise (control) and Premise modified composites with the following bioadditives such as Chitosan $(10 \% \mathrm{w} / \mathrm{w})$, Chitosan/ $\beta$-Carotene $(5: 110 \% \mathrm{w} / \mathrm{w})$, Guar Gum Resin $(10 \%$ $\mathrm{w} / \mathrm{w})$, or $\beta$-Carotene $(10 \% \mathrm{w} / \mathrm{w})$ respectively. Volumetric change was measured with an electronic mercury dilatometer $[3,6]$.

\section{Experimental}

Morphology of the "bioactive restorative materials": The samples were prepared by freezing in liquid nitrogen for $10 \mathrm{~min}$, and then were freeze-dried for $24 \mathrm{~h}$. The prepared samples were fractured in liquid nitrogen using a razor blade. The fractured samples were dried under vacuum, attached to metal stubs, and sputter coated with gold under vacuum for the SEM study. The interior and the surface morphology were observed under scanning electron microscope (SEM, Hitachi S4800, Japan).

Volumetric Shrinkage: Three samples from each material groups were light cured for 25.0 seconds at $800 \mathrm{~mW} / \mathrm{cm}^{2}$ (Dentsply/Caulk Spectrum 800 halogen).The curing output was monitored with a Caulk (Milford, Germany) radiometer to ensure an output of $800 \mathrm{~mW} / \mathrm{cm}^{2} \pm 50 \mathrm{~mW} / \mathrm{cm}^{2}$. Calibration of the electronic mercury dilatometer was done as described previously prior to every specimen test[6]. The Teflon specimen holder has a hole with a diameter of $5.0 \mathrm{~mm}$ and a height of $2.5 \mathrm{~mm}$ resulting in the specimen volume of $49.087 \mathrm{~mm}^{3}$. The dilatometer was kept in a temperature controlled incubator at the $25^{\circ} \mathrm{C} \pm 1^{\circ} \mathrm{C}$. The room temperature was kept constant at $25^{\circ} \mathrm{C} \pm 1$ during dilatometry testing [10, 11-15].

Vickers Hardness: The surface micro-hardness was determined with a Vickers Hardness tester (ZwickRoelldurometer, ZHV1/2 Micro-Vickers, Italy) using a Vickers diamond indenter HV0.5 (500gf) load with a dwell time of 15 seconds (Ramp, 2006).Five samples were prepared for each as Premise (control), Chitosan $(10 \% \mathrm{w} / \mathrm{w})$, Chitosan $/ \beta$-Carotene (5:1 $10 \% w / w)$, Guar Gum Resin $(10 \% w / w)$, or $\beta$-Carotene $(10 \% \mathrm{w} / \mathrm{w})$ under laboratory conditions for the Vickers Hardness. A standard Teflon mould was used with diameter of $5.0 \mathrm{~mm}$ and a height of $2.5 \mathrm{~mm}$ resulting in the specimen volume of $49.087 \mathrm{~mm}^{3}$. The light cured samples were placed in the specimen holders on a moist paper towel and kept $\mathrm{T} 34^{\circ} \mathrm{C} \pm 1$ for 48 hours in a temperature controlled incubator. The surface of the sample was prepared with 1000 grit silicon carbide paper and then 2000 grit (3M, Massachusets, USA) until about $100 \mu \mathrm{m}$ has been removed from the surface layer. The five indentations of the five samples were taken and an average was calculated for each material.

Five indentations were made in accordance with ASTM E384: Standard Test Method for Knoop and Vickers Hardness of Materials. The distance between indentations were 2.5 the indentation size. The distance from the centre of the indentation to the edge of the specimen was also 2.5 the indentation size. 
Shear bond strength tests for dentin bonding: Fifty six teeth samples were divided into 7 groups of 8 each and prepared using the methodology summarized in (TABLE 1) for the corresponding groups A-G and stored in a solution of artificial saliva. Extracted non-carious, intact, human molars stored in water containing a few crystals of thymolat $4^{\circ} \mathrm{C}$ were used within two months using protocol previously described by us.

These groups were then treated as outlined in TABLE 1. After 24 hours one stud of the two of each tooth was tested for shear bond strength. An Instron Universal Testing Machine at a crosshead speed of $0.5 \mathrm{~mm} /$ minute was used to test the de-bonding strength. All data were analyzed for statistical significance using theKruskal-Wallis test, $\mathrm{p}<0.05$.

Flexural strength properties: The flexural strength properties of "bio-active" modified light-cured composite resins.

The specimens were fabricated according to the manufacturers' instructions, ISO 404913 and ANSI/ADA specification n.27.

For the three-point flexural strength test, 10 bar-shaped specimens were fabricated from each composite resin, following the manufacturer's instructions and ISO4049[16]. The composite resin was packed inside a stainless steel mold positioned on a glass slab. A thin glass slab was positioned on the mold containing the material, which was light-cured (XL1500, 3M Dental Products, light intensity $>450 \mathrm{~mW} / \mathrm{cm}^{2}$ ) for $20 \mathrm{~s}$ at each third of the upper and lower surfaces of the specimen $(25 \pm 2 \mathrm{~mm} \times 2 \pm 0.1 \mathrm{~mm} \times$ $2 \pm 0.1 \mathrm{~mm}$ ). All specimens were removed from the mold and polished using a $600 \mathrm{gritSiC}$ paper to remove excess material. The dimensions of specimens were checked using a digital caliper (Digimatic caliper, Mitutoyo Corp., Tokyo, Japan). The specimens were then stored in distilled water at $37^{\circ} \mathrm{C}$ for $24 \mathrm{~h}$.Specimens were submitted to the three-point bending test in a universal testing machine (Instron, Australia) at a crosshead speed of 0.5 $\mathrm{mm} / \mathrm{min}$ until fracture [15-19].

The maximum fracture load ( $\mathrm{F}$, in $\mathrm{N}$ ) of each specimen was recorded, and the flexural strength $\left(\sigma_{f}\right)$, in MPa, was calculated as follows:

$\sigma_{\mathrm{f}}=3 \mathrm{Fl} / 2 \mathrm{bh} 2(2)$ where:

$\mathrm{l}$ : distance between the supporting rollers $(20 \mathrm{~mm})$;

b: specimen width $(\sim 2 \mathrm{~mm})$;

h: specimen height $(\sim 2 \mathrm{~mm})$

Results were statistically analyzed using analysis of variance (ANOVA) and Post Hoc multiple comparison test at a significance level of $5 \%$.

\section{Results and Discussion}

\section{Characterization of prepared flowable composite materials}

Scanning electron microscope characterization of the bio-active restorative materials: The SEM images were obtained to characterize the microstructure of the freeze-dried gels and are presented in (Figure 1). The 'skin' of the prepared modified flowable composites can be seen, and the collapse of the surface pores may be due to artifacts (freeze-drying process).

The SEM images of the tooth surfaces exposed to the modified Premise composites are summarized in (Figure 2a) after 24 hours and (Figure $2 \mathrm{~b}$ ) after 6 month of bonding to the dentin.

Volumetric shrinkage of the bioactive restorative materials: Volumetric changes due to polymerization in modified composites have been explored using an electronic mercury dilatometer and results are summarized in (Figures 3 and 4).

The average volumetric change reached a plato at about 20 seconds for the samples tested and the total volumetric changes were reached at 25 seconds. The average for the control Premise samples had a total volumetric change of $2.74 \%$. Guar/Premise had the largest volumetric change from all the modified Premise samples (2.41\%). The Chitosan/Premise $(1.07 \%)$ had the least volumetric change, followed by $\beta$-Carotene/Chitosan/Premise (1.63\%) and $\beta$-Carotene/Premise (1.75\%).

The volumetric change starts at different time intervals for

Table 1: Groups tested (8 teeth per groups).

Group A $37 \%$ of phosphoric acid + primer+ Bonding immediately (negative control)

Group B Self-etching primer + Bonding immediately (positive control)

Group C Self-etching primer + Bonding immediately (Composite)

Group Self-etching primer + Bonding immediately (Composite) D Chitosan)

Group E Self-etching primer + Bonding immediately (Composite/ $\beta$ Group E $\begin{aligned} & \text { Self-etching } \\ & \text { carotene) }\end{aligned}$

Group F Self-etching primer + Bonding immediately (Comp/ $\beta$ Group F carotene/Chitosan) Group G $\begin{aligned} & \text { Self-etching primer + Bonding immediately (Comp/Guar } \\ & \text { Gum) }\end{aligned}$
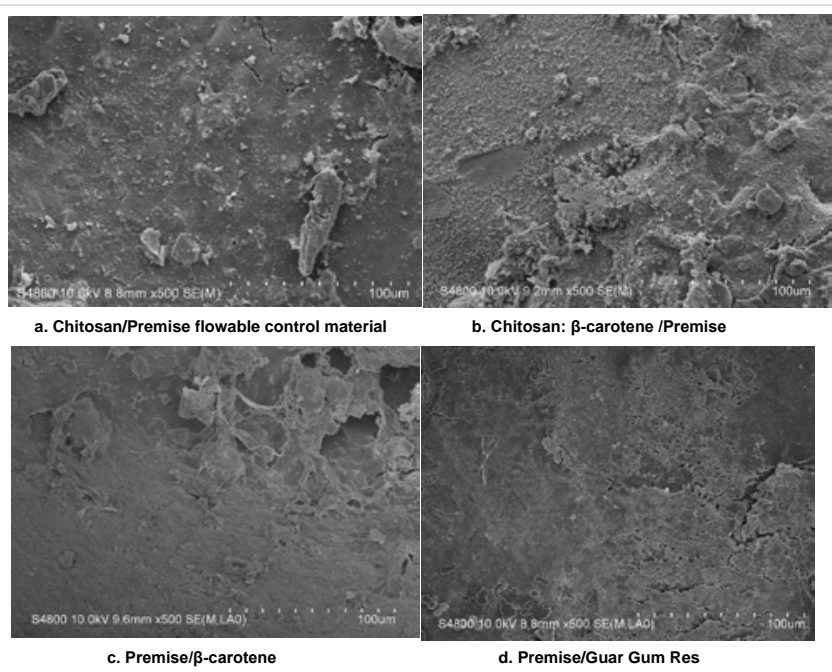

Figure 1: SEM- surfaces of the materials after polymerization where a) Chitosan/Premise flowable control material b) Chitosan: $\beta$-carotene / Premise c) Premise $/ \beta$-carotene d) Premise/Guar Gum Res. 

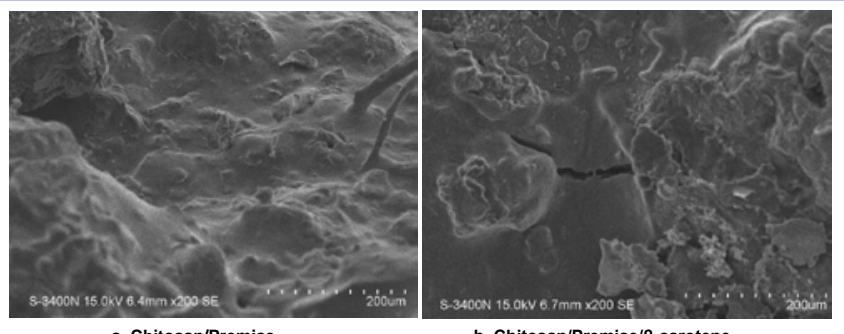

a. Chitosan/Premise

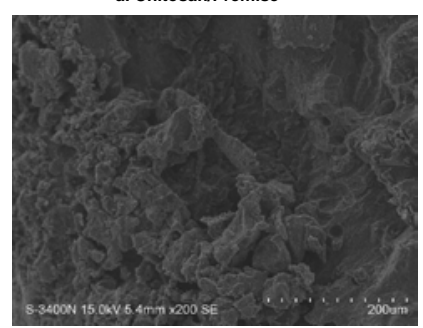

c. Premise/ $\beta$-carotene

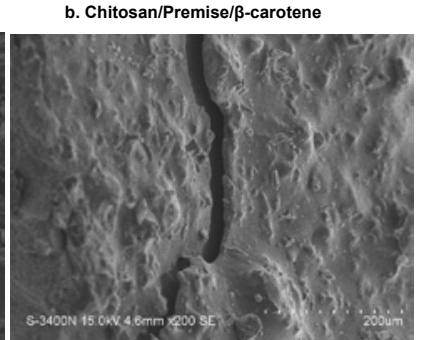

d. Premise/Guar Gum Resin

Figure 2a: Surface of materials after 24 hours in artificial saliva where a) Chitosan/Premise, b)Chitosan/Premise/ $\beta$-carotene, c)Premise/ $\beta$ carotene and d) Premise/Guar Gum Resin.

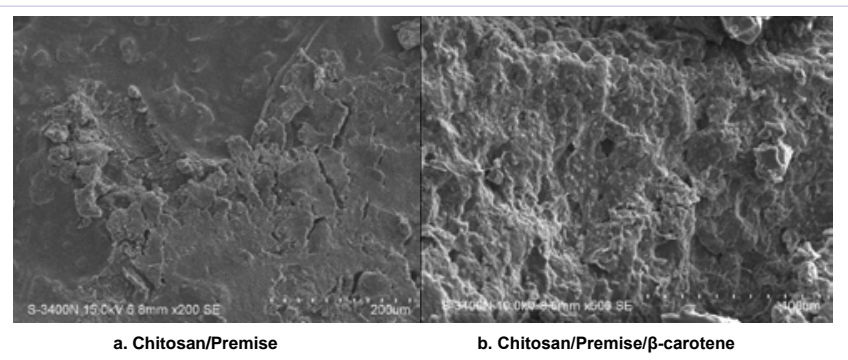

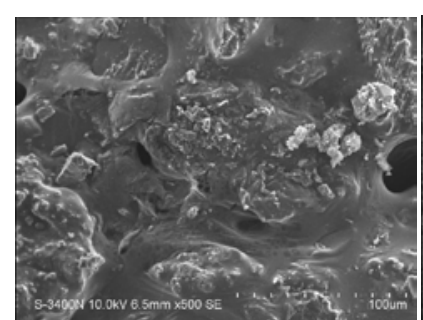

c. Premise/ $\beta$-carotene b. Chitosan/Premise/ $\beta$-carotene

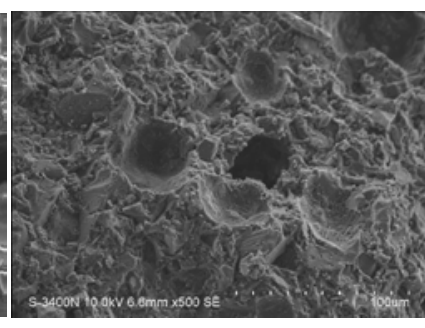

d. Premise/Guar Gum Resin
Figure 2b: Surface of materials after 3 month in artificial saliva a) Chitosan/Premise b) Chitosan/Premise/ $\beta$-carotene, c) Premise/ $\beta$-carotene and d) Premise/Guar Gum Resin.

Average volumetric change of 4 modified flowable composites vs Premise Co ntrol

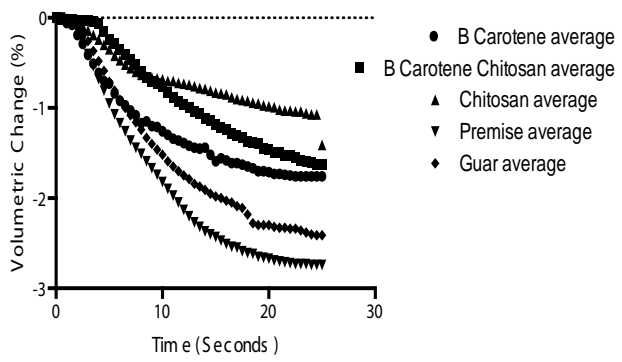

Figure 3: Volumetric change over a 25 second irradiation period of 4 modified flowable composites vs Premise Control.

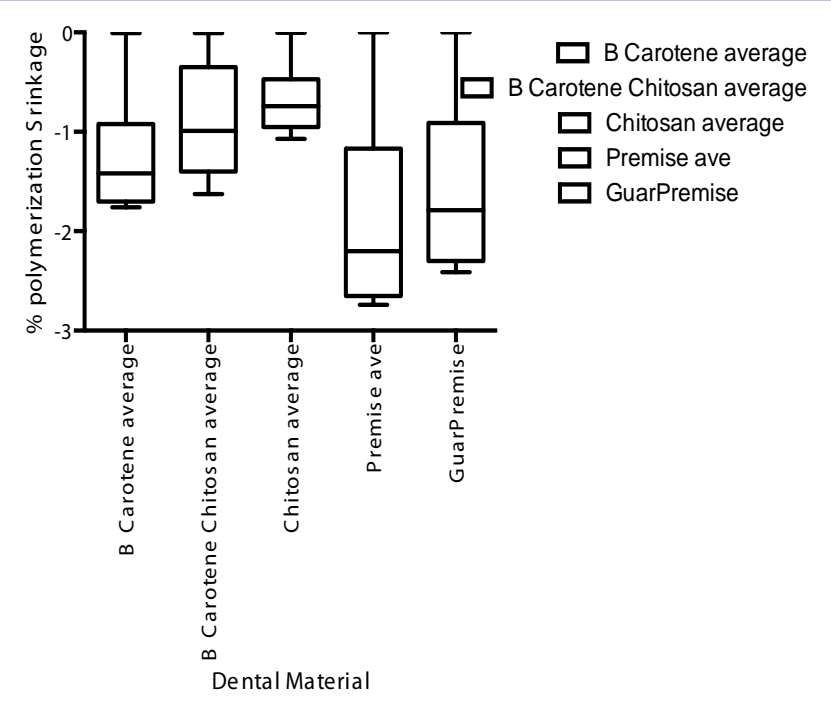

Figure 4: The Box and Whisker plot of volumetric change over a 25 second irradiation period of 4 modified flowable composites vs Premise Control. The Turkey-Kramer multiple comparison test on the rate of shrinkage slopes has confirmed the statements $(\mathrm{p}<0.05)$.

all the materials. The Premise control and Guar/Premise started to show volumetric change at second 1.0 followed $\beta$-carotene/ Premise, $\beta$-carotene/Chitosan/Premise, Chitosan/Premise at second 0.5. The Turkey-Kramer multiple comparison test on the rate of shrinkage slopes has confirmed the statements $(\mathrm{p}<0.05)$.

Vickers Hardness of the bioactive restorative materials: The fact that the average Vickers Hardness between the samples of the average of $\beta$ carotene/chitosan/Premise (37.4VH), Guar Gum/Premise (36.2VH), $\beta$-carotene/Premise $(36 \mathrm{VH})$ were so close to the Premise control $(37.6 \mathrm{VH})$ it can be deduced that the decrease volumetric change was not due to a decreased conversion rate but rather the larger methacrylate molecule that was present in the Premise combinations. It is well documented that it is insoluble under alkaline and neutral conditions,but can react with inorganic and organic acids such as hydrochloric acid, lactic acid,acetic acid and glutamic acid under acidic conditions. It has $\mathrm{OH}$ and $\mathrm{NH}_{2}$ groups that give rise to hydrogen bonding and these groups could act as nucleophilic agent to initiate the polymerization of methyl methacrylate leading to an irreversible attachment between chitosan and methyl methacrylate through different multipoint linkages [20].

The Chitosan/Premise however was influenced significantly since the Vickers Hardness was only 5.2. When the Premiseflowable/Chitosan samples were removed from the specimen holder it was noted that a layer of about $0.5 \mathrm{~mm}$ was not cured and still soft.This would suggest that possibly more free radical inhibition occurs or the slower rate of shrinkage would result in a greater bond strength and possibly lower stress within the restoration and tooth interface.

Bond strength testing: The shear bond strength values (MPa) of the composite restorative materials were given after 24 hours (Figure 5) as well as after 6 months (figure 6). 
Mean shear bond strength values and difference between the groups are summarized in Figure 3 for bonding to dentin after 24 hours and Figure 4 after 6 month. In general there was an increase in bond strength of the dentin treated with the "bioactive restorative materials complex containing bio-adhesive chitosan and the combination of the chitosan/beta-carotene or guar gum resin compared to the bond strength of the conventionally bonded teeth.

The results of this study suggests that the optimum results for the strengthening of dentin can be achieved throughout the immediate interaction with collagen fibers of dentin:chitosana well as interaction of chitosan:organic core of the flowable material complex with the increase of dentin bond strength.

Therefore the newly developed chitosan derivatized systems, are supporting our earlier reported results be able to address the shortfalls affecting the long-term bonding performance of modern adhesives and addresses the current perspectives for improving bond durability of conventional adhesive systems as demonstrated in our "in vitro" model system.

Flexural strength of the modified restorative materials: The mean and standard deviation values (MPa) for the flexural strength are summarized in (Figure 7).

All modified bio-active flowable composites, which an exception of chitosan and $\beta$-carotene containing materials have shown comparable compressive and flexural strength to the commercially available Premise material which makes the newly modified bioactive composites ideal candidates for further evaluation and development is bio-functional restorative materials.

Studies of equilibrium swelling in modified bio-active composites and Premise flowable material as a standard were measured.The "bioactive restorative materials" remain in the cylindrical form after swelling. Compared with dry state

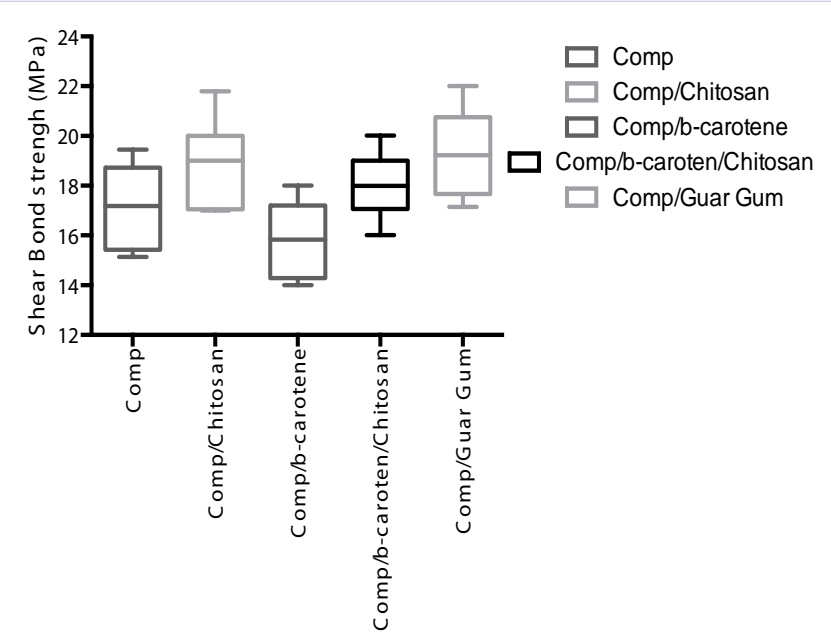

Figure 5: Shear bond strength of modified composites after 24 hours of bonding to dentin of the Premise (Standard) versus modified "bioactive" composites. The Turkey-Kramer multiple comparison test on the rate of shrinkage slopes has confirmed the statements $(\mathrm{p}<0.05)$.

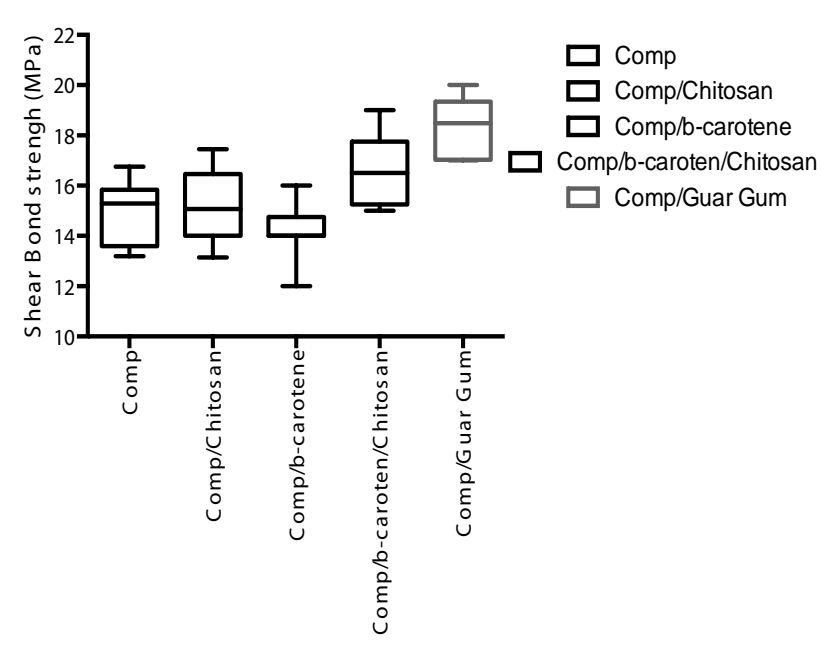

Figure 6: Shear bond strength of modified composites after 6 month of bonding to dentin of the Premise (Standard) versus modified "bioactive" composites. The Turkey-Kramer multiple comparison test on the rate of shrinkage slopes has confirmed the statements $(\mathrm{p}<0.05)$.

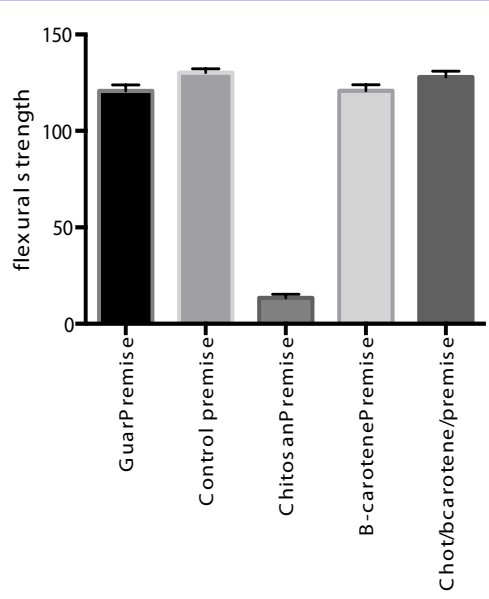

Figure 7: Flexural strength of the modified restorative materials of modified composites of Premise (Control) versus modified "bioactive" composites such as (GuarPremise, ChitosanPremise, $\beta$-carotenePremise and Chitosan/ $\beta$-carotene/Premise) respectively. Post Hoc multiple comparison test at a significance level of $5 \%$.

composites, the volume of the swollen state hydrogel does not display a significant increase as summarized in (Figure 8).

\section{Conclusions}

The materials were tested using effective in-vitro development of "dual function restorative materials". We quantified the effects of functional designer biomaterials on the dentin bond strength of a composite, measure volumetric change due to polymerization in dental resins as well as Vickers hardness and $\%$ of water uptake by the modified composites. Within the limitations of the study design chitosan based hydrogels are suitable materials for functional restorative applications in vitro. Cytotoxicity data is currently being evaluated in our laboratory. The clinical significance is that the decrease in volumetric change 


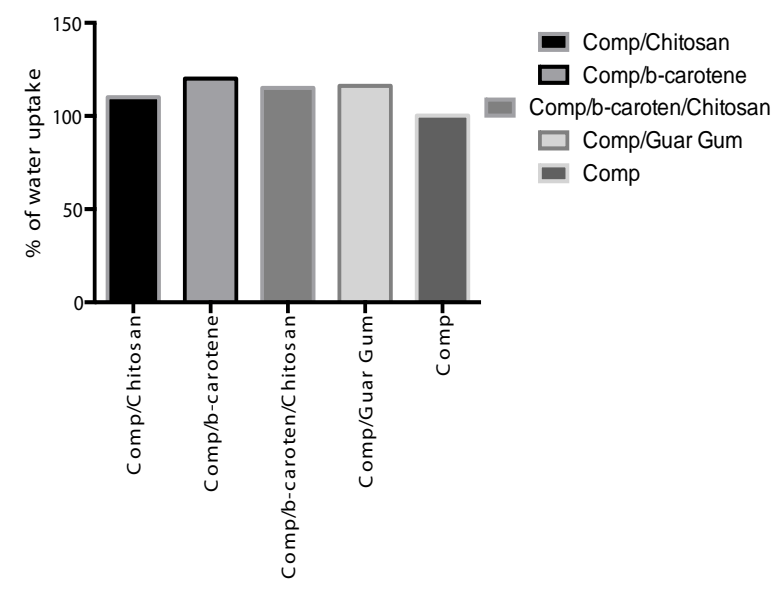

Figure 8: Degree of water uptake of the modified composites such as Premise (Comp) as Standard, Comp/Chitosan, Comp/ $\beta$-carotene, Comp/ $\beta$-carotene/Chitosan and Comp/Guar Gum.

will have a positive effect on the stress formation on the tooth/ adhesive/restoration interface.

\section{References}

1. PeiR,LeeJH,Shih NJ,Chen M,TerasakiPI.Singlehumanleukocyteantigen flow cytometry beads for accurate identification of human leukocyte antigen antibody specificities. Transplantation. 2003;75(1):43-49.

2. Zachary AA, Ratner LE, Graziani JA, Lucas DP, Delaney NL, Leffell MS. Characterization of HLA class I specific antibodies by ELISA using solubilized antigen targets: II. Clinical relevance. Hum Immunol. 200;62(3):236-246.

3. Claas FHJ. Clinical relevance of circulating donor-specific HLA antibodies. Curr Opin Organ Transplant. 2010;15(4):462-466. doi: 10.1097/MOT.0b013e32833b9c38.

4. Loupy A, Hill GS, Jordan SC. The impact of donor-specific anti-HLA antibodies on late kidney allograft failure. Nat Rev Nephrol. 2012;8(6):348-357. doi: 10.1038/nrneph.2012.81.

5. Susal C, Opelz G. Impact of HLA matching and HLA antibodies in organ transplantation: a collaborative transplant study view. Methods Mol Biol. 2012;882:267-277. doi: 10.1007/978-1-61779-842-9_15.

6. Dragun D, Müller DN, Bräsen JH, Fritsche L, Nieminen-Kelhä M, Dechend $\mathrm{R}$, et al. Angiotensin II type 1-receptor activating antibodies in renalallograft rejection. N Engl J Med. 2005;352(6):558-569.

7. Dragun D, Philippe A, Catar R. Role of non-HLA antibodies in organ transplantation. Curr Opin Organ Transplant. 2012;17(4):440-445. doi: 10.1097/MOT.0b013e328355f12b.

8. Sumitran-Holgersson, Suchitra, Holgersson, Jan. Clinical importance of non-HLA antibodies in solid organ transplantation. Current Opinion in Organ Transplantation: August 2006 - Volume 11 - Issue 4 - p 425432. doi: 10.1097/01.mot.0000236708.13823.d2

9. Zou Y, Stastny P, Susal C, Döhler B, Opelz G. Antibodies against MICA antigens and kidney-transplant rejection. N Engl J Med. 2007;357(13):1293-1300.

10. Kalil J, Guilherme L, Neumann J, Rosales C, Marin M, Saldanha L, et al. Humoral rejection in two HLA identical living related donor kidney transplants. Transplant Proc. 1989;21(1 Pt 1):711-713.

11. Holgersson J, Elsheikh E, Grufman P, Sumitran-Holgersson S, Tydén G.
A case of acute vascular rejection caused by endothelial-reactive nonHLA antibodies. Clin Transpl. 2006:535-538.

12. Sumitran-Karuppan S, Tyden G, Reinholt F, Berg U, Moller E. Hyperacute rejections of two consecutive renal allografts and early loss of the third transplant caused by non-HLA antibodies specific for endothelial cells. Transpl Immunol. 1997;5(4):321-327.

13. Opelz G; Collaborative Transplant Study. Non-HLA transplantation immunity revealed by lymphocytotoxic antibodies. Lancet. 2005;365(9470):1570-1576.

14. Glotz D, Lucchiari N, Pegaz-Fiornet B, Suberbielle-Boissel C. Endothelial cells as targets of allograft rejection. Transplantation. 2006;82(1 Suppl):S19-S21.

15. Le Bas-Bernardet S, Hourmant M, Coupel S, Bignon JD, Soulillou JP, Charreau B. Non-HLA-type endothelial cell reactive alloantibodies in pre-transplant sera of kidney recipients trigger apoptosis. Am J Transplant. 2003;3(2):167-177.

16. Breimer ME, Rydberg L, Jackson AM, Lucas DP, Zachary AA, Melancon $\mathrm{JK}$, et al. Multicenter evaluation of a novel endothelial cell crossmatch test in kidney transplantation. Transplantation. 2009;87(4):549-556. doi: 10.1097/TP.0b013e3181949d4e.

17. VermehrenD, Sumitran-HolgerssonS.Isolation of precursorendothelial cells from peripheral blood for donor-specific crossmatching before organ transplantation. Transplantation. 2002;74(11):1479-1486.

18. Terasaki PI, McClelland JD. Microdroplet assay of human serum cytotoxins. Nature. 1964;204:998-1000.

19. Racusen LC, Colvin RB, Solez K, Mihatsch MJ, Halloran PF, Campbell $\mathrm{PM}$, et al. Antibody-mediated rejection criteria - an addition to the Banff 97 classification of renal allograft rejection. Am J Transplant. 2003;3(6):708-714.

20. Jackson AM, Lucas DP, Melancon JK, Desai NM. Clinical relevance and IgG subclass determination of non-HLA antibodies identified using endothelial precursors isolated from donor blood. Transplantation. 2011;92(1):54-60. doi: 10.1097/ TP.0b013e31821b60e9.

21.Jackson AM, Kuperman MB, Montgomery RA. Multiple hyperacute rejections in the absence of detectable complement activation in a patient with endothelial cell reactive antibody. Am J Transplant. 2012;12(6):1643-1649. doi: 10.1111/j.16006143.2011.03955.x.

22. Malek SK, Keys BJ, Kumar S, Milford E, Tullius SG. Racial and ethnic disparities in kidney transplantation. Transpl Int. 2011;24(5):419424. doi: 10.1111/j.1432-2277.2010.01205.x.

23. Kerman RH, Kimball PM, Van Buren CT, Lewis RM, Kahan BD. Possible contribution of prestransplant immune responder status to renal allograft survival differences of black versus white recipients. Transplantation. Transplantation. 1991;51(2):338-342.

24. Kerman RH, Kimball PM, Van Buren CT, Lewis RM, Cavazos D, Heydari $\mathrm{A}$, et al. Influence of race on crossmatch outcome and recipient eligibility for transplantation. Transplantation. 1992;53(1):64-67.

25. Alheim M, Johansson SM, Hauzenberger D, Grufman P, Holgersson J. A flow cytometric crossmatch test for simultaneous detection of antibodies against donor lymphocytes and endothelial precursor cells. Tissue Antigens. 2010;75(3):269-277. doi: 10.1111/j.13990039.2009.01439.x.

26. Qin Z, Zou Y, Lavingia B, Stastny P. Identification of endothelial cell surface antigens encoded by genes other than HLA. A combined 
immunoprecipitation and proteomic approach for the identification of antigens recognized by antibodies against endothelial cells in transplant recipients. Hum Immunol. 2013;74(11):1445-1452. doi: 10.1016/j.humimm.2013.05.002.

27. Sigdel TK, Sarwal MM. Moving beyond HLA: a review of nHLA antibodies in organ transplantation. Hum Immunol. 2013;74(11):1486-1490. doi: 10.1016/j.humimm.2013.07.001.

28. Stastny P. Introduction: what we know about antibodies produced by transplant recipients against donor antigens not encoded by HLA genes. Hum Immunol. 2013;74(11):1421-1424. doi: 10.1016/j. humimm.2013.05.004. 